\title{
DÜBLIN
}

Technological University Dublin ARROW@TU Dublin

1996-01-01

\section{Rotating Disk Ion Selective Electrodes}

\author{
John Cassidy \\ Technological University Dublin, john.cassidy@tudublin.ie \\ David Mullen \\ Technological University Dublin \\ Karen Casey \\ Technological University Dublin
}

See next page for additional authors

Follow this and additional works at: https://arrow.tudublin.ie/scschcpsart

Part of the Chemistry Commons

\section{Recommended Citation}

Cassidy, J.F., Casey, K., Mullen, D., Cullen, P.:Rotating Disk Ion Selective Electrodes. Electroanalysis, Vol.8., 1996, pp.918-921. doi:10.1002/elan. 1140081013

This Article is brought to you for free and open access by the School of Chemical and Pharmaceutical Sciences at ARROW@TU Dublin. It has been accepted for inclusion in Articles by an authorized administrator of ARROW@TU Dublin. For more information, please contact arrow.admin@tudublin.ie, aisling.coyne@tudublin.ie, gerard.connolly@tudublin.ie.

Funder: Technological University Dublin Seed fund

Scheme. (Grant number 95/42

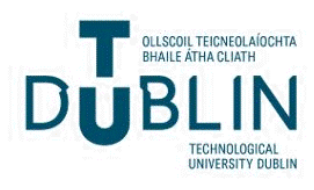




\section{Authors}

John Cassidy, David Mullen, Karen Casey, and Patrick Cullen

This article is available at ARROW@TU Dublin: https://arrow.tudublin.ie/scschcpsart/11 


\title{
Rotating Disk Ion Selective Electrodes
}

\author{
John Cassidy.* David Mullen, Karen Casey, and Patrick Cullen
}

Chemistry Department, Dublin Institute of Technology, Kovin Street, Dublin 8, Ireland

Received: November 15, 1995

Final version: January 18,1996

\begin{abstract}
A simulation was undertaken to predict the transient potential response following a concentration step at a rotating disk electrode comprised of an ion selective layer. A basis for this simulation was that the potential response would be independent of rotation rate since the diffusion layer is larger than the double layer at the electrode. In practice it was found that the potential response does vary with rotation rate. The response was such that the apparent concentration of the analyte in solution decreased with increased rotation rate. The reason for this behavior is due to the disruption of the double layer at the electrode surface by convection.
\end{abstract}

Keywords: Potentiometry, Flowing streams, Rotating disk electrode

\section{Introduction}

The use of potentiometry has maintained a high level of interest both with arrays of sensors which compensate for mutual interferences $[1,2]$ along with their use in flowing streams $[3-5]$. The use of potentiometry in flowing streams has advantages over their use in stagnant solutions namely

(a) Increased potential stability since the Nernst diffusion layer both at the sensing and reference electrode are hydrodynamically defined [3]

(b) No interference from the reference can occur as it may be placed downstream. If a small concentration of the ion to be sensed is in the carrier, this ensures a constant baseline. To examine the nature of the hydrodynamic effects, rotating disk ion selective electrodes (RDEISE) were modelled and used experimentally in chloride, thiocyanate, silver and potassium solutions. The expected potential transient following a concentration step at an RDEISE was calculated and the rotation rate dependence of the potential response is discussed.

\section{Theory}

\subsection{Model for a Concentration Step at an RDEISE}

The membrane is coated on a rotating disk electrode. Region $A$ in Figure 1 is the stagnant layer and region $B$ is the convective layer. Initially the concentration of the analyte in solution is the same in both regions $\left(C_{1}\right)$ and by standard addition the concentration in region $\mathrm{B}$ is increased $\left(C_{2}\right)$ and the analyte ion diffuses into region $\mathrm{A}$. The following equations apply:

$$
\begin{aligned}
& \frac{\partial C_{\mathrm{A}}}{\partial t}=D \frac{\partial^{2} C_{\mathrm{A}}}{\partial x^{2}} \\
& \frac{\partial C_{\mathrm{B}}}{\partial t}=D \frac{\partial^{2} C_{\mathrm{B}}}{\partial x^{2}}-v \frac{\partial C_{\mathrm{B}}}{\partial x}
\end{aligned}
$$

where $v=-0.51 \omega^{3 / 2} v^{-1 / 2} x^{2}[6]$ and the diffusion coefficients of the analyte are taken to be the same in region $\mathrm{A}$ and region $\mathrm{B}$. The stagnant layer thickness is given by $\delta=1.61 \mathrm{D}^{1 / 3} v^{1 / 6} \omega^{-1 / 2}$ $[6,7]$.

For Equations 1 and 2 the initial conditions are that

$$
\left.\begin{array}{rl}
0<x<\delta ; C_{A}(x, 0) & =C_{1} \\
\delta<x<2 \delta ; C_{B}(x, 0) & =C_{2}
\end{array}\right\}
$$

and the boundary conditions are

$$
\begin{aligned}
& \left.\frac{\mathrm{d} C_{\mathrm{A}}}{\mathrm{d} x}\right|_{x=0}=0 \text { and } \\
& \left.\frac{\mathrm{d} C_{\mathrm{A}}}{\mathrm{d} x}\right|_{x=\delta}=\left.\frac{\mathrm{d} C_{\mathrm{B}}}{\mathrm{d} x}\right|_{x=\delta}
\end{aligned}
$$

also that $C_{\mathrm{B}}(x=25, t)=C_{2}$.

The model takes into account slow kinetics where the rate of incorporation of the analyte into the membrane is slow and governed by a pseudo first order rate constant $k$

$$
\text { Analyte }+ \text { site } \stackrel{k}{\longrightarrow} \text { Analyte }
$$

the electrode response is determined by the Nernst equation

$$
E=\text { constant }+S \log \left(C_{\mathrm{A}}(0, t)\right)
$$

where

$$
C_{\mathrm{A}}^{*}(0, t)=C_{\mathrm{A}}(0, t)(1.0-\exp (-k t))
$$

Initially $C_{\mathrm{A}}(0, t)$ is determined by solving Equations 1 and 2 and so finding how quickly species approach the electrode and from this value $C_{A}^{*}(0, t)$ is found using Equation 8 .

In order to solve the equations by collocation dimensionless parameters are used [8-10]. In particular the dimensionless time is given by $\left(T=D t / \delta^{2}\right)$ and the dimensionless rate constant is given by $K=k t=k \delta^{2} T / D$. Note that the dimensionless time and the dimensionless rate are both intrinsically linked to the rotation rate $\omega$.

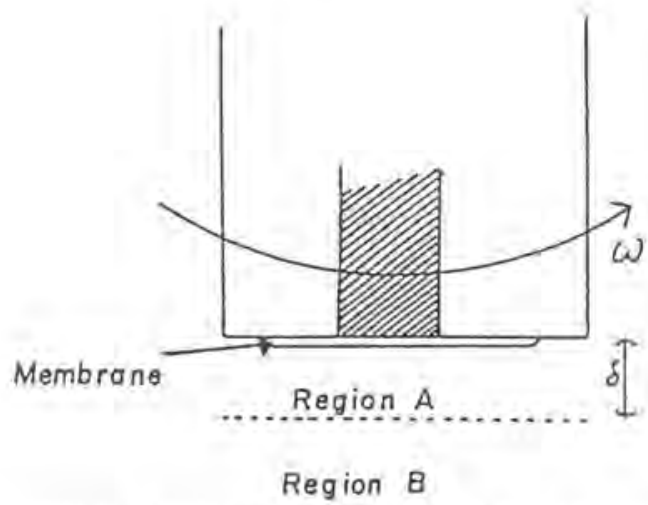

Fig. 1. Schematic for rotating disk ion selective electrode model. 
Table 1. Estimate of dimensions for double layer and diffusion layer thicknesses.

\begin{tabular}{|c|c|c|c|}
\hline$R P M$ & $\begin{array}{l}\text { Diffusion [a] } \\
\text { layer [cm] }\end{array}$ & $\begin{array}{l}\text { concentration } \\
\left(\text { moldm }^{-3} \mid\right.\end{array}$ & $\begin{array}{l}\text { double } \\
\text { layer }[\mathrm{b}][\mathrm{cm}]\end{array}$ \\
\hline 500 & 0.0172 & $10^{-1}$ & $4.4 \times 10^{-7}$ \\
\hline 1000 & 0.0122 & $10^{-2}$ & $1.4 \times 10^{-6}$ \\
\hline 1500 & 0.0099 & $10^{-3}$ & $4.4 \times 10^{-6}$ \\
\hline 2000 & 0.0086 & $10^{-4}$ & $1.4 \times 10^{-5}$ \\
\hline 2500 & 0.0077 & $10^{-5}$ & $4.4 \times 10^{-5}$ \\
\hline 3000 & 0.0071 & & \\
\hline
\end{tabular}

(a) Diffusion layer thickness using diffusion coefficient $=10^{-5} \mathrm{~cm}^{2} \mathrm{~s}^{-1}$ and kinematic viscosity as $0.01 \mathrm{~cm}^{2} \mathrm{~s}^{-1}$.

[b] Approximate double layer thickness worked out for $99 \%$ of the potential drop out in solution using the Guoy-Chapman theory in water at $25^{\circ} \mathrm{C}$ (Eq. 9).

\subsection{Levich-Guoy-Chapman Model}

According to the Guoy-Chapman model for the potential decay away from the surface of a charged layer, a simple exponential may be employed [6].

$$
\phi=\phi^{\circ} \exp (-\kappa x)
$$

where $\kappa=3.29 \times 10^{7}|z| C^{1 / 2}$ for a dilute aqueous solution at $25^{\circ} \mathrm{C}$ when $\phi^{\circ}<50 \mathrm{mV}$. Table 1 consists of thicknesses of double layers and diffusion layers from the Guoy-Chapman and RDE model, respectively. The diffusion layer can be seen to be at least two orders of magnitude larger than the double layer. Ideally the potential should not be perturbed by the rotation . To explain why such an effect is present Equation 9 is modified. If $x=\delta$, then Equation 9 becomes on substitution

$$
\ln \phi=\ln \phi^{0}-5.297 \times 10^{7}|z| C^{1 / 2} D^{1 / 3} v^{1 / 6} \omega^{-1 / 2}
$$

If the potential $\phi$ is measured at the electrode surface then it should be independent of rotation rate but if the potential is measured a little way out in solution then it may depend on the rotation rate according to Equation 10 in which case a plot of In $\phi$ against $\omega^{-1 / 2}$ should be linear.

\section{Experimental}

The membrane was prepared by using PVC $(0.200 \mathrm{~g})$, tricaprylmethylammonium chloride (Aliquat 336S, Aldrich, $0.100 \mathrm{~g})$ in tetrahydrofuran $(10 \mathrm{~mL})$. This was coated on a Metrohm carbon disk electrode and the potentials were measured with respect to a saturated calomel electrode. The other system consisted of a Metrohm silver disk coated with $\mathrm{AgSCN}$ or $\mathrm{AgCl}$ or Metrohm platinum electrodes coated with a potassium ionophore/PVC composite ( $\{$ bis[(benzo-15-crown-5)$4^{\prime}$-ylmethyl] pimelate $\}, 2.8 \%$ w./w., dibutylphthalate, $69.4 \%$ and PVC, $17.8 \%$ made up in tetrahydrofuran [11].

No attempt was made to keep the ionic strength of the solutions constant. When silver solutions were monitored a salt bridge of $10 \% \mathrm{KNO}_{3}$ was employed.

\section{Results and Discussion}

Figure 2(a) is a plot of the simulated potential transient following a tenfold change in concentration as a function of dimensionless time. For $0.1<T<2.2$, a fit of

$$
E(t)=E(\infty)+S \log [1.11-1.05 \exp (T)]
$$

yielded a correlation coefficient value of 0.99 ; this equation has a

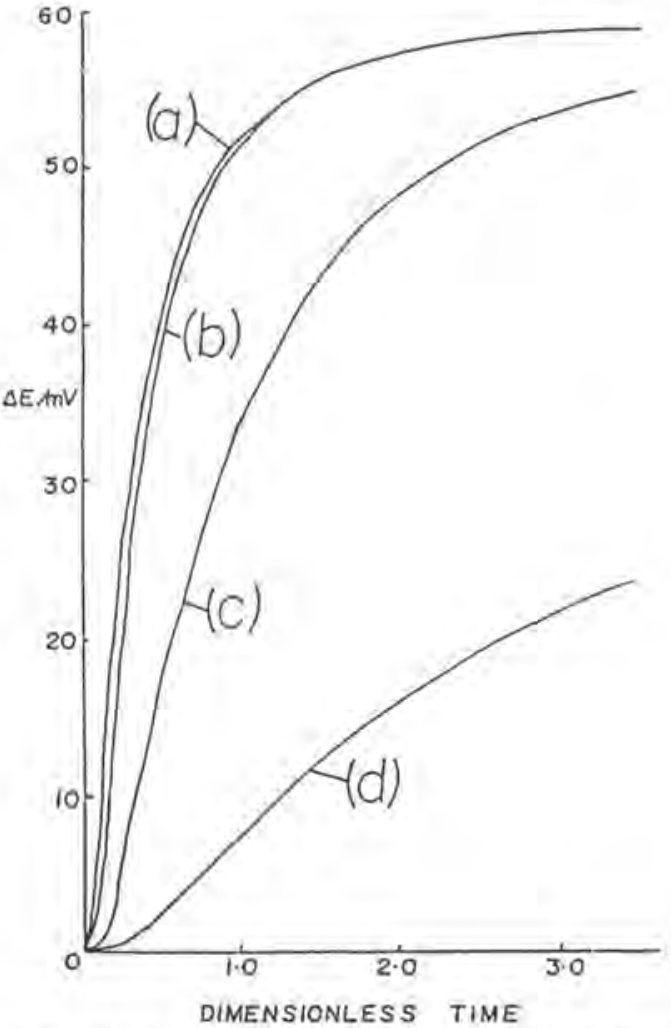

Fig. 2. (a) Simulated concentration step at an RDEISE $C_{1}=10^{-1} \mathrm{M}$, $C_{2}=1.0 \mathrm{M}$, Diffusion coefficient $=10^{-6} \mathrm{~cm}^{2} \mathrm{~s}^{-1}$, rotation rate, $f=10^{3} \mathrm{rpm}, k=\infty$, (b) $k=0.1 \mathrm{~s}^{-1}, f=10 \mathrm{rpm}$, (c) $k=0.1 \mathrm{~s}^{-1}$, $f=10^{2} \mathrm{rpm}$, (d), $k=0.1 \mathrm{~s}^{-1}, f=10^{3} \mathrm{rpm}$.

similar form to those listed elsewhere. for diffusion into a stagnant layer $[12,13]$. At a dimensionless time of 2.2 , this corresponds to $99 \%$ of the limiting potential value and the real time transformation of this is $t=54.5 v^{1 / 3} /\left(R P M \cdot D^{1 / 3}\right)$. If $D$ is $10^{-6} \mathrm{~cm}^{2} \mathrm{~s}^{-1}$ and $v=0.01 \mathrm{~cm}^{2} \mathrm{~s}^{-1}$, then $t=1173 / \mathrm{RPM}$. Thus for $1000 \mathrm{rpm}$, the time it takes to reach the equilibrium potential is quite fast ( $=1.173 \mathrm{~s}$.) following a concentration step should the response be diffusion controlled. When the rate of reaction between the species and the sites is slow, it can be seen that there is a more gradual change in the potential and this is affected by rotation rate as can be seen in Figure 2. It can be seen from Figure 2 that as $\omega$ increases, the potential is lower at a particular dimensionless time. Experimentally potentials were found to be slow to equilibrate for the rotating disk electrode system and in contrast to expectation the potentials did vary systematically with rotation rate.

Figure 3 shows the effect of rotation rate on the potential response of a SCN ${ }^{-}$selective electrode. It was determined that this electrode had a Nerastian behavior $(-59.5 \mathrm{mV} /$ decade change in concentration between $10^{-5}$ to $10^{-1} \mathrm{M} \mathrm{SCN}^{-}$at $20^{\circ} \mathrm{C}$ ). It can be seen in Figure 3 that a linear behavior is obtained but that the slopes of the $\ln (\phi)$ against $1 /(\omega)^{1 / 2}$ plots do not vary with concentration as expected from Equation 10. Equation 10 is however a simplified model since there is convection occurring within the Nernst layer. According to Equation 10, the slope of the plot should increase with increased concentration of the species. This does not seem reasonable since as the ionic strength increases, the double layer should tighten closer to the electrode and the effect of rotation rate should be lower. A further limitation to Equation 10 is that the slopes are of the wrong sign when the equation is applied to the 


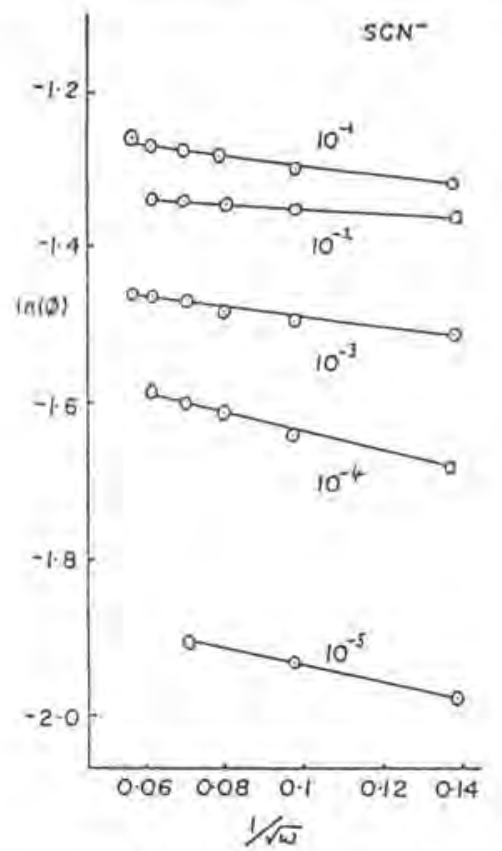

Fig. 3. Potential response of an RDEISE consisting of an aliquat/PVC membrane on a carbon disk as a function of $(\omega)^{-1 / 2}$ as a function of different concentrations of $\mathrm{SCN}^{-}$as indicated in the figure in moles $\mathrm{dm}^{-3}$.

experimental results. This is because the model predicts that the potential decays from $\phi^{\circ}$ as a function of distance out into solution. This will not apply to situations where the potential increases as a function of distance out into solution. Equation 9 is therefore empirical and experimentally the disruption of the double layer due to convection leads to an apparent decrease in concentration of the species sensed. Experimentally the behavior follows the equations

$$
\begin{aligned}
& \ln (\phi)=\ln \left(\phi^{\circ}\right)-\text { constant }(\omega)^{-1 / 2} \text { for anions and } \\
& \ln (\phi)=\ln \left(\phi^{\circ}\right)+\text { constant }(\omega)^{-1 / 2} \text { for cations }
\end{aligned}
$$

An attempt was made to explain the potential/rotation rate behavior using streaming potentials. The Smoluchowski [14] and Helmholtz-Smoluchowski [15] equations were used along with the Bernoulli equation to relate the potential changes to flow rates and thus rotation rates. However, in each case these models predicted that the potential should increase with rotation rate and so do not appear to be appropriate models.

Figure 4 shows similar behavior for a chloride electrode, though this particular electrode was not ideally Nernstian; it had a straight line relationship between potential and log concentration but the slope was only $-37 \mathrm{mV} /$ decade. Once again the change in potential with rotation rate is greater at lower concentrations; though there is a rotation rate dependence even. at $0.1 \mathrm{M}$ chloride.

Figure 5 shows linear behavior between $\log$ of the $E$ and $(\omega)^{-1 / 2}$ for systems consisting of $\mathrm{AgX}$ as an $\mathrm{RDE}$ where $\mathrm{X}$ is either $\mathrm{Cl}^{-}$or $\mathrm{SCN}^{-}$. It can be seen that there is still a rotation rate dependence of the form in Equation 12 showing that it not an effect caused by the mechanical effects of PVC coatings in the earlier results.

Figure 6 shows results for the $\mathrm{Ag} / \mathrm{AgCl}$ system in $\mathrm{Ag}^{+}$ solutions and also a $\mathrm{Pt}$ electrode coated with the ionophore for potassium in $10^{-4}$ moldm ${ }^{-3}$ potassium ion. Though the behavior is nonlinear, the effect is similar to that mentioned

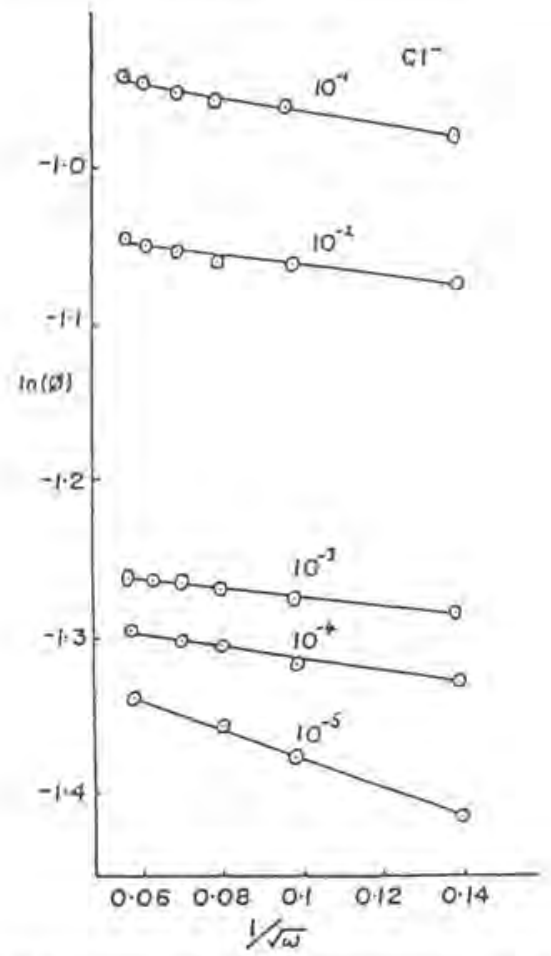

Fig. 4. Potential response of an RDEISE consisting of an aliquat/PVC membrane coated on a carbon disk as a function of $(\omega)^{-1 / 2}$ as a function of different concentrations of $\mathrm{Cl}^{-}$as indicated in the figure in moles. $\mathrm{dm}^{-3}$.

previously. As the rotation rate increases, the apparent concentration of the species (as monitored by the measured potential) decreases. This implies that there is a convective process within the diffusion layer. How can this be if the magnitudes of the diffusion and double layers are so different as shown in Table 12

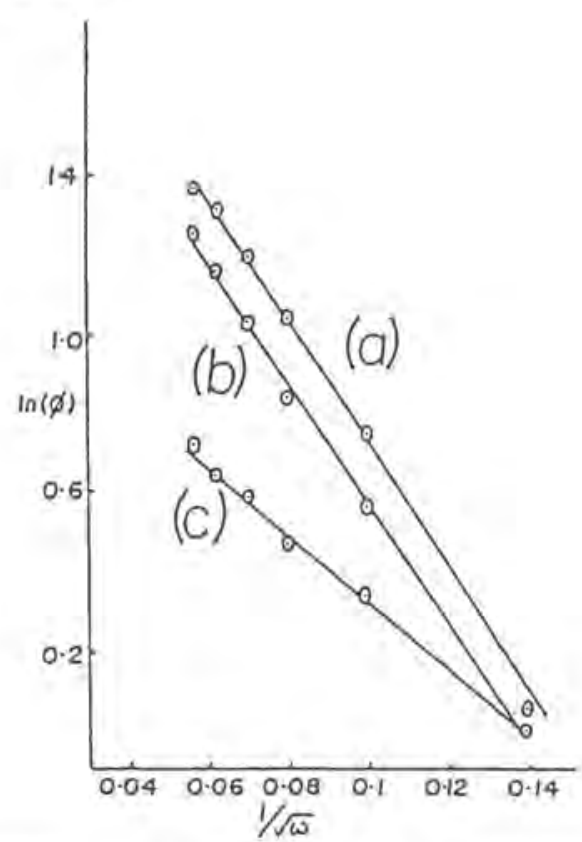

Fig. 5. Corrected potentials as a function of rotation rate for silver/silver halide RDEISE in various solutions. (a) $10^{-3} \mathrm{M} \mathrm{KSCN}$ where the corrected potential is $E-33 \mathrm{mV}$. (b) $10^{-3} \mathrm{M} \mathrm{KCl}$ where the corrected potential is $E-157 \mathrm{mV}$ and (c) $10^{-4} \mathrm{MKSCN}$ where the corrected potential is E-81.1 mV. 


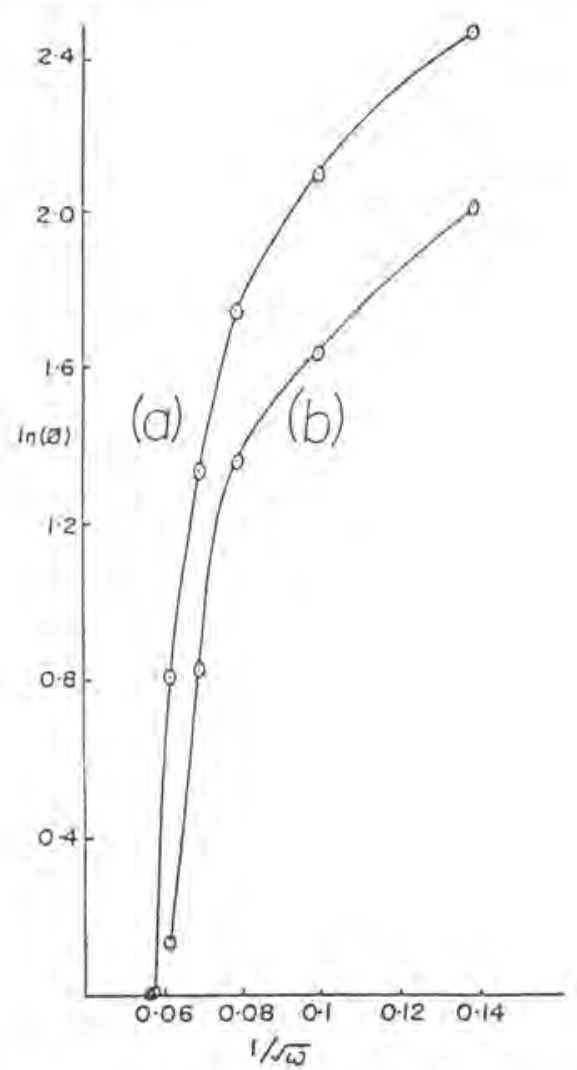

Fig. 6. Corrected potentials as a function of rotation rate for RDEISE in various solutions. (a) potassium ionophore on $\mathrm{Pt}$ with $\mathrm{KCl}=10^{-4} \mathrm{M}$, corrected potential is $\mathrm{E}+287.9 \mathrm{mV}$ and (b) $\mathrm{Ag} / \mathrm{AgCl}$ electrode in $10^{-4} \mathrm{M}$ $\mathrm{AgNO}_{3}$, corrected potential $=E-333 \mathrm{mV}$.

The answer is that the diffusion layer thickness is purely a model based on the Nernst layer thickness. In the simplified treatment for an amperometric response; the current is the value that would be obtained for a system with an equivalent diffusion layer thickness of $\delta$. In fact there is convection close to the electrode. The magnitude of the velocity of the solution perpendicular to the disk is given by [6]

$$
V_{x}=(\omega v)^{1 / 2}\left[-0.51023 \gamma^{2}+\gamma^{3 / 3}-\ldots\right]
$$

where $y=(\omega / \nu)^{1 / 2}, x$ is the distance away from the electrode and v) is the kinematic viscosity. When $x=1.4 \times 10^{-6} \mathrm{~cm}$ at $3000 \mathrm{rpm}$, the velocity is $5.56 \times 10^{-8} \mathrm{~cm} / \mathrm{s}$ compared to $x=0.0071 \mathrm{~cm}$, at $3000 \mathrm{rpm}, V_{\mathrm{x}}=0.257 \mathrm{~cm} / \mathrm{s}$. So even though the velocity at the double layer is small, it appears to have an effect on the potential response due to a disruption of the double layer induced by the flow of solution past the double layer. It can be seen that Figure 2 predicts a similar situation as Figure 6 but according to the model there is no change in the steady state response and as such the slow kinetics model is not appropriate.

\section{Conclusion}

These experiments show that the potential response depends on rotation rate. The model is therefore incomplete in that no attempt was made to include the effect of the rotation rate, except by means of a rate constant. These experiments indicate that the space charge density or the double layer is affected by convection. This in turn affects the equilibrium response since the space charge density is affected even at high concentrations and low rotation rates. This will be a consideration in all situations where ISE's are used; in stirred solutions or flowing streams factors such as viscosity and ionic strength will therefore be important. Further potentiometric work will be carried out on the $\left[\mathrm{Fe}(\mathrm{CN})_{6}\right]^{3-/ 4-}$ system at a rotating platinum electrode. Work will also be done on rotation rate step potentiometric experiments.

\section{Acknowledgements}

J.C. would like to thank DIT for financial support under the DIT Seed fund Scheme. (Grant number 95/42) Helpful discussions with Prof. D.E. Williams, Prof. P.N. Bartlett, Dr. K. Doblhofer, Dr. V. Cunnane, Dr. M.E.G. Lyons and Dr. P.M. Kelly are gratefully acknowledged.

\section{References.}

[1] R.J. Forster, F. Regan, D. Diamond, Anal. Chem. 1991, 63, 876.

[2] J.A. Shatkin, H. Szejnwald Brown, S. Licht, Anal. Chem, 1995, 67, 1147.

[3] K. Cammann, Fresnius J. Anal. Chem. 1988, 329, 691.

[4] R.Y. Xie, G.D. Christian, Anal. Chem. 1986, 58, 1806,

[5] A. Izquierdo, M.D. Luque de Castro, Electroanalysis 1995, 7, 505.

[6] A.J. Bard, L.R. Faulkner, Electrochemical Methods, Wiley, New York 1981.

[7] J. Newman, J.Phys.Chemt. 1966, 70, 1327.

[8] S. Pons in Electroanalytical Chemistry, Vol. 13 (Ed: A.J. Bard), New York, 1984, p.115.

[9] J. Cassidy, W. Breen, M.E.G. Lyons, Electroanalysis 1991, 3, 293.

[10] J.F. Cassidy, W. Breen, A. McGe, J.G. Vosand M.E.G. Lyons, Electroanalysis 1992, 4, 751.

[11] Selectophore Ionophores for Ion Selective Electrodes and Optodes, Fluka, Buchs, Switzerland, 1991.

[12] H. Freiser, Ion Selective Electrodes in Analytical Chemistry, Plenum, New York, 1978

[13] W.E. Morf, The Principles of Ion Selective Electrodes and Membrane Transport, Elsevier, Amsterdam, 1981.

[I4] D. Shaw, Introduction to Colloid Chemistry, 4th. ed., ButterworthHeineman, Oxford, 1992.

[15] P.Van den Winkel, J. Mertens, D.L. Massart, Anal, Chem. 1974, 46, 1765. 